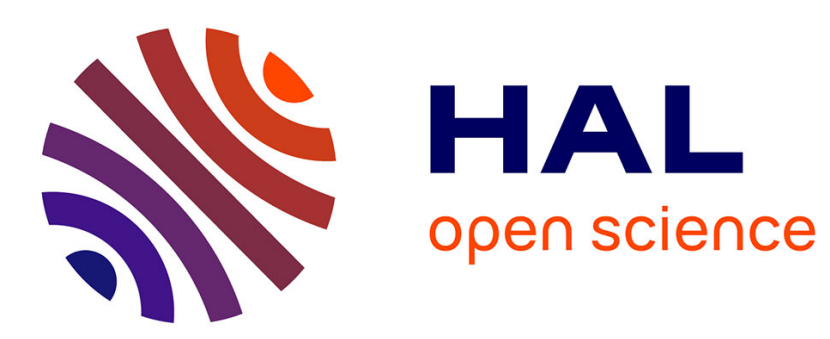

\title{
Characterization of the Mullins effect of carbon-black filled rubber
}

Yannick Merckel, Julie Diani, Mathias Brieu, Pierre Gilormini, Julien Caillard

\section{To cite this version:}

Yannick Merckel, Julie Diani, Mathias Brieu, Pierre Gilormini, Julien Caillard. Characterization of the Mullins effect of carbon-black filled rubber. Rubber Chemistry and Technology, 2011, 84 (3), pp.402 - 414. 10.5254/1.3592294. hal-00656178

\section{HAL Id: hal-00656178 https://hal.science/hal-00656178}

Submitted on $20 \mathrm{Jul} 2020$

HAL is a multi-disciplinary open access archive for the deposit and dissemination of scientific research documents, whether they are published or not. The documents may come from teaching and research institutions in France or abroad, or from public or private research centers.
L'archive ouverte pluridisciplinaire HAL, est destinée au dépôt et à la diffusion de documents scientifiques de niveau recherche, publiés ou non, émanant des établissements d'enseignement et de recherche français ou étrangers, des laboratoires publics ou privés. 


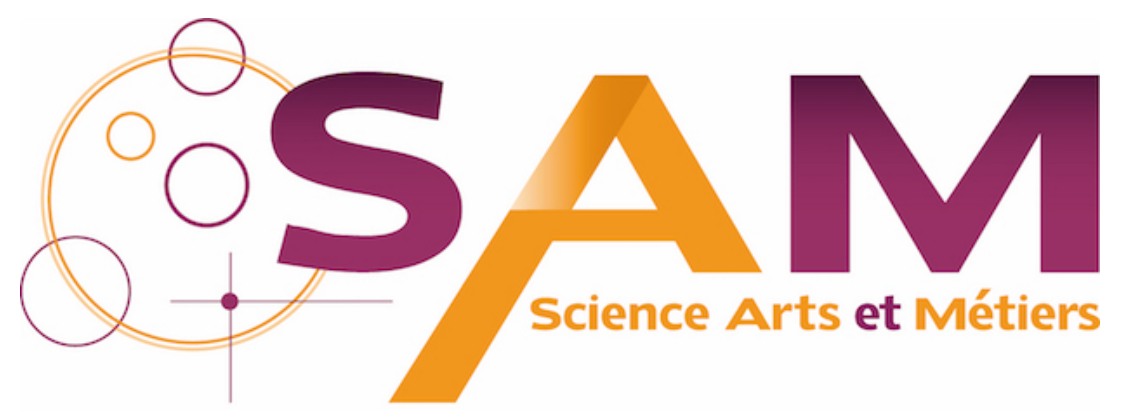

Archive Ouverte - Open Repository

\section{Science Arts \& Métiers (SAM)}

is an open access repository that collects the work of Arts et Métiers ParisTech researchers and makes it freely available over the web where possible.

This is an author-deposited version published in: https://sam.ensam.eu Handle ID: .http://hdl.handle.net/10985/6804

\section{To cite this version :}

Yannick MERCKEL, Julie DIANI, Mathias BRIEU, Pierre GILORMINI, Julien CAILLARD Charcaterization of the Mullins effect of carbon-black filled rubbers - Rubber Chemistry and Technology - Vol. 84, n³, p.402-414 - 2011 


\title{
CHARACTERIZATION OF THE MULLINS EFFECT OF CARBON-BLACK FILLED RUBBERS
}

\author{
Yannick Merckel $^{\mathrm{a}}$, Julie Diani ${ }^{\mathrm{b}}$, Mathias Brieu $^{\mathrm{a}}$, Pierre Gilormini $^{\mathrm{b}}$, Julien Caillard $^{\mathrm{c}}$
}

${ }^{\text {a }}$ LML, Ecole Centrale de Lille, bd Paul Langevin, 59650 Villeneuve d'Ascq, FRANCE.

b PIMM, CNRS, Arts et Métiers ParisTech, 151 bd de l'Hôpital, 75013 Paris, FRANCE.

${ }^{\mathrm{c}}$ Manufacture Française de Pneumatiques Michelin, CERL, Ladoux, 63040 Clermont-Ferrand, FRANCE.

email: yannick.merckel@ec-lille.fr - tel: +33 3203353 51; fax: +33 320335377

email: julie.diani@ensam.eu - tel : +33 1442461 92; fax: +33144246290

email: mathias.brieu@ec-lille.fr - tel : +33 32033 53 75; fax: +33 320335393

email: pierre.gilormini@ensam.eu - tel : + 331442463 37; fax: +33 144246290

email: julien.caillard@fr.michelin.com - tel : +33 4731078 42; fax: +33 473106129.

\begin{abstract}
Several carbon-black filled styrene-butadiene rubbers showed different sensibilities to the Mullins softening when submitted to cyclic uniaxial tension. In order to quantify this softening, a damage parameter was introduced. It is defined by using a classic damage approach and can be estimated by using either the strain amplification factor method or the tangent modulus at zero stress. The proposed parameter is used to study the effects of crosslink density and filler amount on the Mullins softening. The latter is shown to remain unaffected by a change of crosslink density and to increase with an increase of filler amount. The damage parameter exhibits mere linear dependences on the maximum Hencky strain applied and on the filler volume fraction. A simple linear expression is given finally to predict the Mullins softening of filled rubbers. The parameter also provides an objective analysis for the Mullins softening that supports comments on a better understanding of this effect.
\end{abstract}




\section{INTRODUCTION}

The Mullins effect is a stress softening noticed in filled and crystallizing rubbers when first loaded above the maximum strain ever applied. It has been evidenced in $1903^{1}$ and later Mullins and his co-authors explored the phenomenon intensively ${ }^{2-5}$. The literature reports a large amount of experimental evidence of the phenomenon (see Table $1^{6}$ ). Also, several mechanical modelings emerged during the past three decades in order to reproduce the stress-strain responses of rubbers exhibiting Mullins softening ${ }^{6-10}$. Nonetheless, these contributions lack of defining an objective quantitative parameter that would allow the comparison of one material to others. Such a parameter would also permit to study the influence of the material composition on the Mullins softening. The aim of the present contribution is to propose such an objective parameter.

For this purpose, several carbon-black filled styrene butadiene rubbers (SBR) characterized by their crosslink densities and their carbon-black volume fractions were submitted to cyclic uniaxial tension tests. A classic damage parameter was proposed using the strain amplification factor introduced $\mathrm{in}^{11}$ and reworked and completed $\mathrm{in}^{9,12-16}$. This approach compares the stress-strain responses of a material submitted to various levels of maximum strain on the entire strain range, which can cover several hundred percent. Here, the strain amplification factor has been revised using the Hencky (or logarithmic) strain as the measure of strain. This modification will prove to provide simpler results that can be corroborated by the study of the evolution of the Young's modulus at small strain. Qualitative comparisons of the tensile modulus after softening can be found in the literature ${ }^{5}$, but no attempt of a quantitative comparison. In this contribution, we carried out such a comparison for several materials submitted to various levels of maximum strain. Hence, the introduced damage parameter was estimated for each material. The damage parameter showed a linear dependence on the maximum strain. This simple dependence allows a direct comparison of the parameter for different loading conditions and various materials.

The paper is ordered as follows. The next section presents the material strategy and the mechanical tests that were conducted. Then the basic idea and the method to estimate the softening are exposed. Finally, results are reported and analyzed, and concluding remarks close the paper. 


\section{MATERIALS AND EXPERIMENTS}

\section{MATERIALS}

For this study, Michelin prepared various N347 carbon-black filled styrene-butadiene rubbers (SBR). Structure (DBP) and Fineness (BET) of the N347 carbon-black are approximately 120 $(\mathrm{ml} / 100 \mathrm{~g})$ and $90\left(\mathrm{~m}^{2} / \mathrm{g}\right)$ respectively, and more information of the microstructure of these fillers may be found $\mathrm{in}^{17}$. The SBR gum is a star-branched solution SBR containing $28 \%$ of styrene and characterized by a molar mass of $\mathrm{M}_{\mathrm{n}}=13310^{3} \mathrm{~g} / \mathrm{mol}$ and an entanglement density close to $4210^{-5}$ $\mathrm{mol} / \mathrm{cm}^{3}$. Its DSC glass transtition temperature is $\sim-48{ }^{\circ} \mathrm{C}$. The material strategy was to vary the amount of fillers and the crosslink density $N_{c}$ by varying the amount of crosslinker (sulfur), in order to identify the effect of each of these parameters. From the reference material B2, materials B1, B3 and B4 were obtained by changing the filler amount from $40 \mathrm{phr}$ to 30,50 and $60 \mathrm{phr}$ respectively. Materials A2, C2 and D2 contain the same amount of fillers than material B2 but their crosslink densities vary. Figure 1 illustrates how each material compares to others. Details of the compositions of materials A2, B2, C2 and D2 are listed in Table I. The lists of filler volume fractions and of crosslink densities measured by swelling appear in Table II. The crosslink density in material A2 is very close to the maximum that can be reached with the material mix considered here.

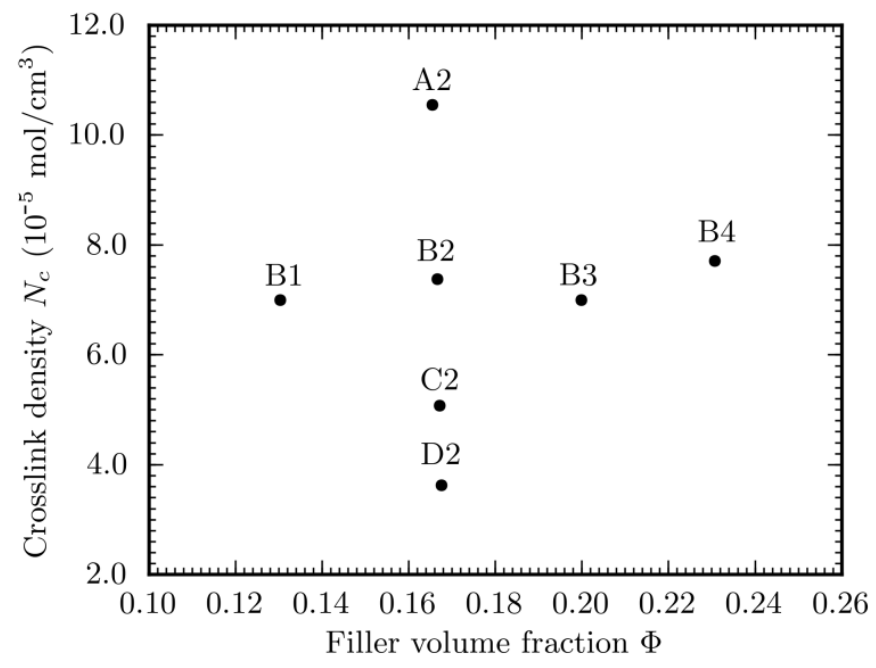

FIG. 1. Material strategy. 
TABLE I

MATERIAL COMPOSITION IN PARTS PER HUNDRED RUBBER (PHR)

\begin{tabular}{lllll}
\hline Ingredient & A2 & B2 & C2 & D2 \\
\hline SBR & 100 & 100 & 100 & 100 \\
Carbon-black (N347) & 40 & 40 & 40 & 40 \\
Antioxidant (6PPD) & 1.9 & 1.9 & 1.0 & 1.9 \\
Stearic acid & 2.0 & 2.0 & 0 & 2.0 \\
Zinc oxide & 2.5 & 2.5 & 0 & 2.5 \\
Structol ZEH & 0 & 0 & 3 & 0 \\
Accelerator (CBS) & 2.3 & 1.6 & 1.5 & 1.0 \\
Sulfur & 2.3 & 1.6 & 1.5 & 1.0 \\
\hline
\end{tabular}

TABLE II

CROSSLINK DENSITY $N_{C}$ AND FILLER VOLUME FRACTION $\Phi$

\begin{tabular}{llllllll}
\hline Material & B1 & B2 & B3 & B4 & A2 & C2 & D2 \\
\hline Crosslink density $N_{c}\left(\mathrm{~mol} / \mathrm{cm}^{3}\right)$ & 8.16 & 7.38 & 8.26 & 7.71 & 10.55 & 5.08 & 3.63 \\
Filler volume fraction $\Phi$ & 13.03 & 16.65 & 19.98 & 23.06 & 16.54 & 16.71 & 16.75 \\
\hline
\end{tabular}

\section{MECHANICAL TESTING}

Mechanical tests were performed on an Instron 5882 uniaxial testing machine. Flat dumbbell specimens of geometry, $30 \mathrm{~mm}$ long, $4 \mathrm{~mm}$ wide and $2.5 \mathrm{~mm}$ thick, were considered. The force was measured by a $2 \mathrm{kN}$ load cell. Local strain measures were obtained by a video extensometer. Except when mentioned, tests were run in displacement control at a constant low crosshead speed of 0.3 $\mathrm{mm} / \mathrm{s}$. Samples were submitted to cyclic loading until break. At each cycle, the maximum strain was increased with a step of $h=\ln \lambda=0.1\left(\lambda=1 / 1_{0}\right.$ being the sample uniaxial stretch), the minimum of the cycles was set to a null force. Figure 2 illustrates the cyclic stress-strain response of our materials during the cyclic uniaxial tension test. As expected for filled rubbers, the materials show a substantial stress softening when first loaded to an amount of strain never applied before. The materials evidence a clear Mullins effect. 


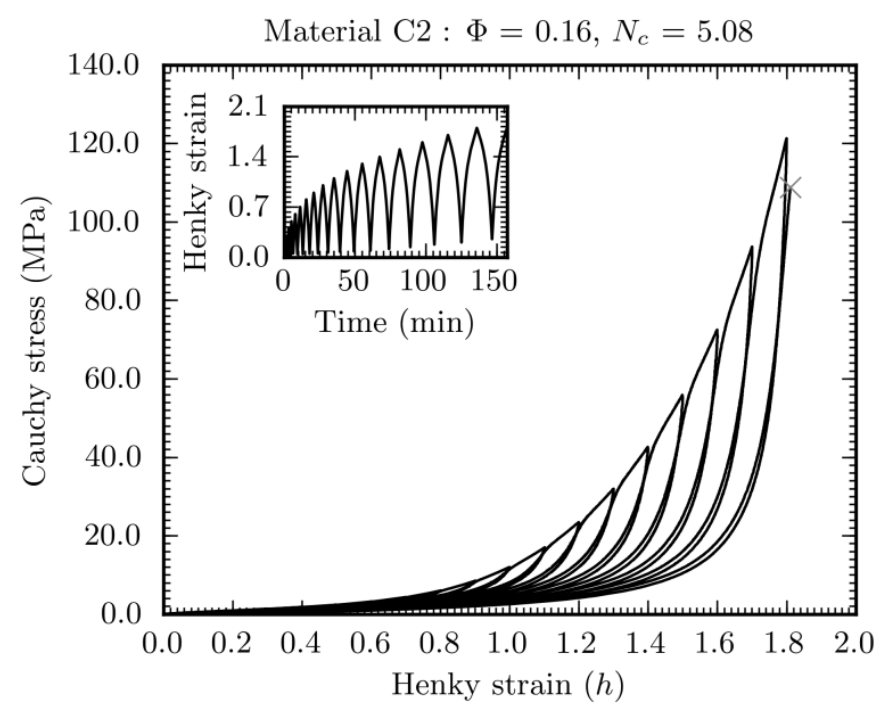

FIG. 2. Material C2 stress-strain response to a uniaxial tensile cyclic test with an increasing maximum strain at each cycle.

The interest of such a loading as used in Figure 2 stands mainly in its simplicity. But the resulting Mullins effect is difficult to quantify and, worse, its quantitative comparison from one material to another is almost impossible without processing the data. In the next section we introduce an original method for the data analysis that will provide a softening parameter $D$ that quantifies the Mullins effect.

\section{CHARACTERIZATION OF THE MULLINS EFFECT}

\section{BASIC IDEA}

The effects of adding fillers to a non-crystallizing rubber gum is first to increase its stiffness and second to introduce some stress-softening when first loaded due to the Mullins effect. The reinforcing effect of fillers may be accounted for by using the strain amplification factor concept ${ }^{11}$ according to which, the mechanical response of the filled gum extended to a stretch $\lambda$ is similar to the mechanical response of the pure gum extended to a stretch $1+X(\lambda-1)$. Here, we extend the strain amplification factor concept to the Hencky strain variable, $h=\ln (\lambda)$, and the strain experienced by the gum is assumed as being the strain in the material virgin of any load magnified by a strain amplification factor $X$ : 


$$
h^{\text {gum }}=X h^{\text {virgin }}
$$

Since it is a reinforcing factor, $X \geq 1$. The parameter $X$ is known to depend mainly on the volume fraction of fillers $\Phi$. It is commonly assumed that $X=1$ when $\Phi=0$, which asserts that the virgin material and the gum coincide when no filler is added. Adopting the model proposed by ${ }^{8}$, based on a physical understanding of the Mullins softening by an irreversible breakdown of filler clusters and chain desorption at the filler-gum interface, the strain amplification factor is assumed to be altered by the maximum strain applied. These authors defined the variable $X$ as dependent on the maximum strain applied, $X\left(h_{\max }\right)$. The problem with such a definition of $X$ is that it is difficult to isolate the softening effect from the reinforcing effect. For this reason, we introduce a damage parameter $D$, depending on the maximum strain and on the material parameters, which renders the fact that the strain amplification is lowered in the composite material due to the Mullins effect. This is expressed by the relation,

$$
h^{\text {virgin }}=(1-D) h^{\text {comp }}
$$

The parameter $D$ characterizes the Mullins softening.

At small strain, the mechanical behavior resulting from a uniaxial tensile test is characterized by the Young modulus $E$. The stress and strain measures used in this study are the Cauchy stress $\sigma=F / S$ ( $F$ and $S$ being the force and the current cross-sectional area) and the Hencky strain respectively, and the modulus is defined by:

$$
\sigma=E h
$$

A quantitative account of the stiffening effect of rigid fillers in a rubber gum was first proposed by Smallwood $^{18}$, who extended the theoretical results obtained by Einstein ${ }^{19}$ regarding the hydrodynamic effect resulting from the addition of rigid particles in a fluid. The tensile modulus of the filled gum is related to the tensile modulus of the pure gum through a factor $X$ depending on the amount of fillers,

$$
E^{\text {virgin }}=X E^{\text {gum }}
$$


One notes that within the small strain assumption, equations (1) and (4) are strictly equivalent. A short review of the various expressions of $X$ applying in (4) and reported in the literature may be found in ${ }^{20}$.

The consequence of the Mullins softening on the Young modulus of filled rubbers was generally appraised from a qualitative point of view ${ }^{5}$. In order to precisely compare the softening at large strain and at small strain, we introduce the damage variable $D$ in the very same way as commonly done for the strain amplification factor (2). This damage parameter depends on the maximum strain already applied to the material and on the material parameters. It provides a link between the actual material stiffness $E^{\text {comp }}$ and the virgin composite stiffness $E^{\text {virgin: }}$

$$
E^{\text {comp }}=(1-D) E^{\text {virgin }}
$$

At this point, equations (2) and (5) define a similar parameter $D$, uniaxial tensile tests are now used to determine the changes of $D$ according to the maximum strain applied, the applied strain rate or the material compositions (amount of fillers and crosslink density). Details of the procedure determining $D$ are provided in what follows.

\section{LOADING VS. UNLOADING STRESS-STRAIN RESPONSES}

During a cyclic loading-unloading-reloading, the viscoelastic effect of the material is more pronounced on the reloading path than on the unloading path, since most of the viscoelastic stress contribution is evacuated at the beginning of the unloading as it is observed in Figure 3. 


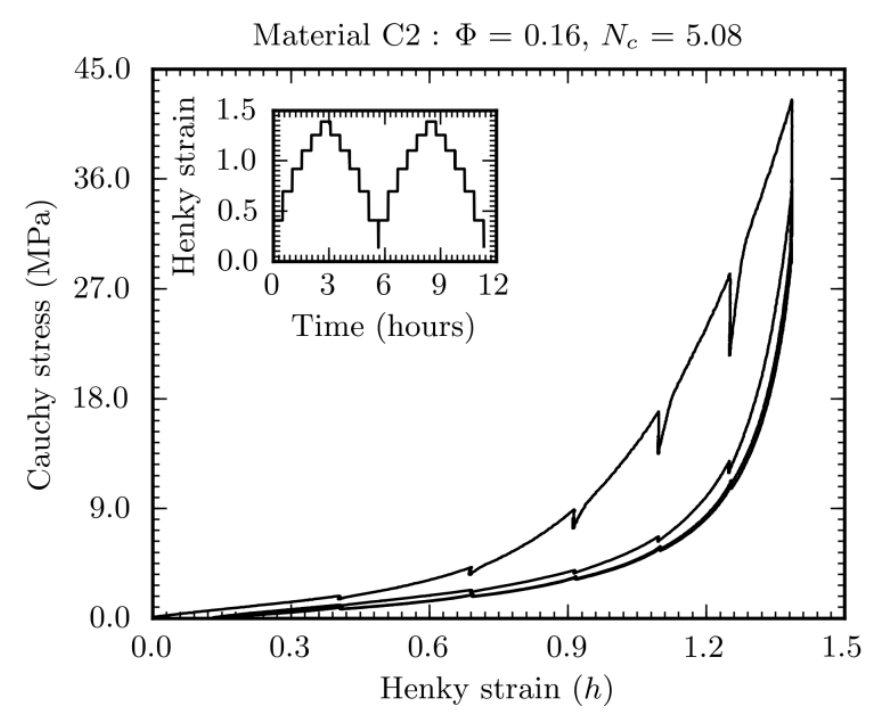

FIG. 3. Material C2 stress-strain response during a cyclic test with a 30-minute relaxation step every $50 \%$ strain step.

The viscoelastic effect is even more critical at small strain, when the initial modulus is estimated. Actually, when changing from the unloading to loading, loading strain rate changes from negative to positive. The large change in the strain rate introduces a viscoelastic contribution to the stress that affects the measure of the tensile modulus. Figure 4 shows the stress-strain response of material $\mathrm{C} 2$ during the first few cycles. One recognizes a substantial increase in the modulus at the very beginning of reloading. This increase does not appear at the end of the unloading, since the strain rate is stabilized when the stress goes to zero. In order to avoid the possible disturbance introduced by viscoelasticity, we adopt the unloading stress-strain responses as the material softened responses in the next sections. 


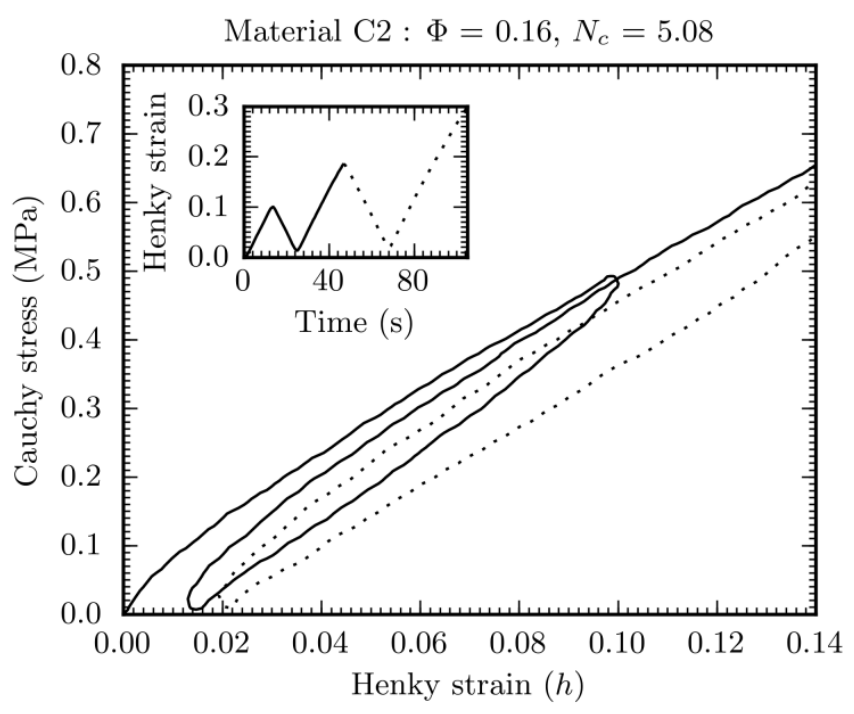

FIG. 4. Material C2 stress-strain response at the first few cycles of the cyclic tensile test. Experimental data were smoothed by a moving window average for a clearer reading.

\section{ESTIMATE OF THE SOFTENING PARAMETER D}

We start with explaining how values of the parameter $D$ defined in large strain by equation (2) are extracted from the experimental data consisting of the unloading stress-strain responses measured during cyclic uniaxial tension. These stress-strain responses are convenient because fast to obtain, but they do not picture the stress-strain responses that would be measured by a user ignorant of the loading history. Actually, one may notice a substantial permanent set $\lambda^{\text {perm }}$ at the end of each unloading, which increases with the maximum strain applied. This permanent set lowers the actual strain undergone by the material. Therefore, in order to reach the stress-strain response $\left(\lambda^{\text {comp }}, \sigma\right)$, that a user unaware of the loading history would measure experimentally, we need to change the data $\left(\lambda^{\text {meas }}, \sigma\right)$ into $\left(\lambda^{\text {comp }}, \sigma\right)$ using the relation:

$$
\lambda^{\text {comp }}=\lambda^{\text {meas }} / \lambda^{\text {comp }}
$$

Let us note that when using the Hencky strain, the latter relation transforms into $h^{\text {comp }}=h^{\text {meas }}-h^{\text {perm }}$. Therefore, accounting for the permanent set simplifies into a mere horizontal shift of the material unloading responses. Figure 6 illustrates the stress-strain responses of material $\mathrm{C} 2$ that 
are finally used after the permanent set horizontal shift has been applied on the data reported in Figure 2.

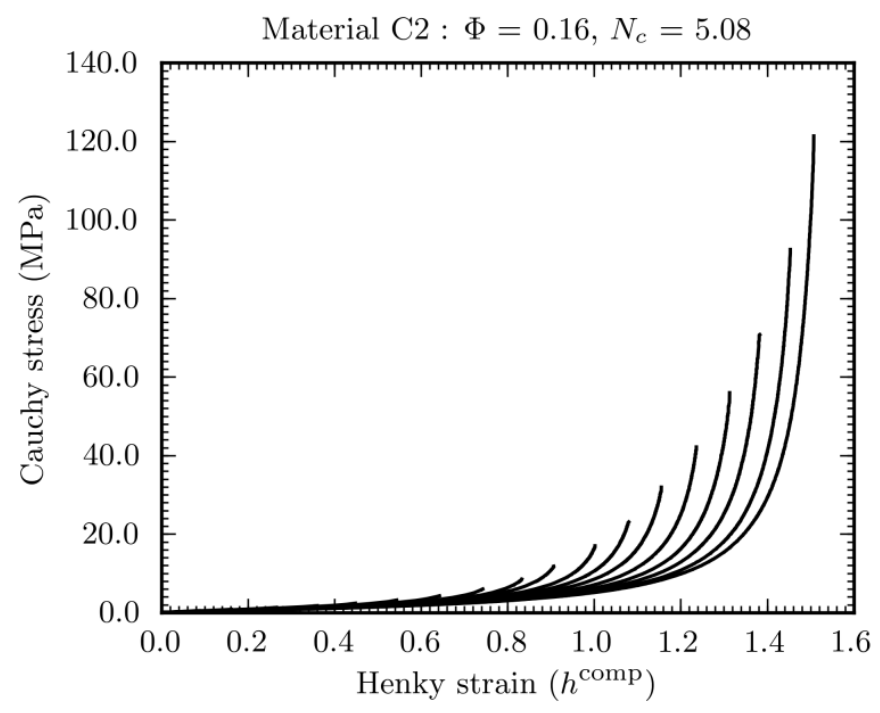

FIG. 5. Stress-strain responses of material C2 softened by previous loadings to various strain levels.

According to equation (2), each softened stress-strain response is related to the same virtual virgin material behavior through the constant parameter $D\left(h_{\max }^{\operatorname{comp}}\right) D\left(h_{\max }^{c o m p}\right) . h_{\max }^{c o m p}$ The stress-strain response of the virgin material defines a master curve that is obtained by superimposing the unloading stress-strain responses thanks to equation (2). When the material is virgin $h_{\max }^{\text {comp }}=0$ and $D=0$; for any other value of $h_{\max }^{\operatorname{comp}}$ the $D$ value is computed by a superimposition fit using a least squares minimization. Figure 6 shows the results of the superimposition method on the stress-strain responses of material C2 (Figure 5). First, one notes that good superimposition is obtained, except near the maximum strain of the unloading responses. The observed discrepancy is partly due to the large relaxation experienced at the beginning of the first unloadings by materials undergoing some Mullins effect. This discrepancy could be reduced by using the second cycle unloading responses. The observed superimposition justifies the use of equation (2) and supports the concept of a virtual virgin material behavior. Second, the inset figure in Figure 6 presents the values of $D$ vs. $h_{\text {max }}^{\text {comp }}$ resulting from the fitting procedure. These values increase with the maximum strain applied, and they show a linear trend that favors the use of the Hencky strain as the strain measure. This linear trend is in good agreement with previous results ${ }^{8}$ that show an exponential evolution of $D$ vs. the maximum stretch. 


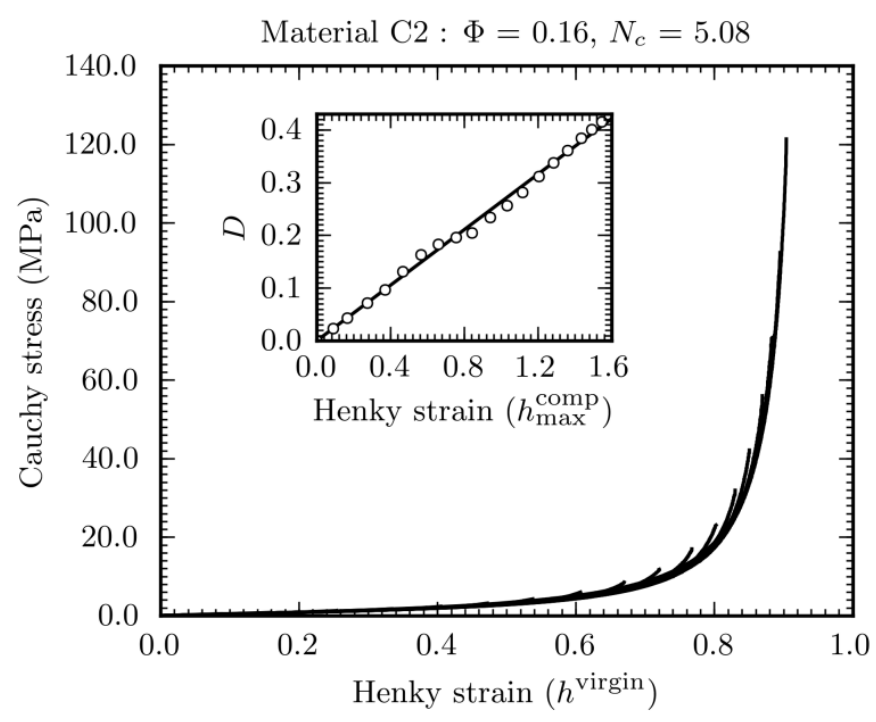

FIG. 6. Material C2 master curve obtained by superimposition of the stress-strain responses plotted in Figure 5. In the inset figure, the values of the damage parameter $D$ that provide superimposition are shown.

Another way to estimate $D$ is to use the tangent modulus. The Young modulus defined by (3) is estimated by calculating the initial tangent modulus,

$$
E^{c o m p}=d \sigma /\left.d h^{c o m p}\right|_{\sigma=0}
$$

Values of this modulus are obtained from on the unloading stress-strain responses by determining the slopes of the linear approximations as it is shown in Figure 7 for material C2. The stress upper limit was chosen at $0.2 \mathrm{MPa}$ and is materialized in Figure 7 by a dashed line. This limit provides a good compromise between the need for having enough experimental data for an accurate estimate of the slope and the need for preserving the linearity of the mechanical behavior. Figure 8 presents the values of the initial tangent modulus for the unloading stress-strain responses characterized by the maximum strain applied $h_{\max }^{\operatorname{comp}}$. One notes that the initial tangent modulus is linearly dependent of $h_{\text {max }}^{\text {comp }}$ except for the very few cycles corresponding to low maximum strains. The discrepancy observed for the first cycles may result from the viscoelastic effect which can hardly stabilize due to the duration of the unloading. Therefore, we always neglected the first few cycles and assumed that the initial tangent modulus is linearly dependent of $h_{\max }^{\operatorname{comp}}$. The linear approximation of the evolution of the initial tangent modulus of material C2 vs. $h_{\max }^{\operatorname{comp}}$ is represented by a dashed line in Figure 8 . This linear 
approximation provides an estimate for the tangent modulus of the virtual virgin material, which is defined by $E\left(h_{\max }^{\operatorname{comp}}=0\right)$. From this approximation and equation (5), values of parameter $D$ are computed according to:

$$
D=1-E^{\text {comp }} / E^{\text {virgin }}
$$

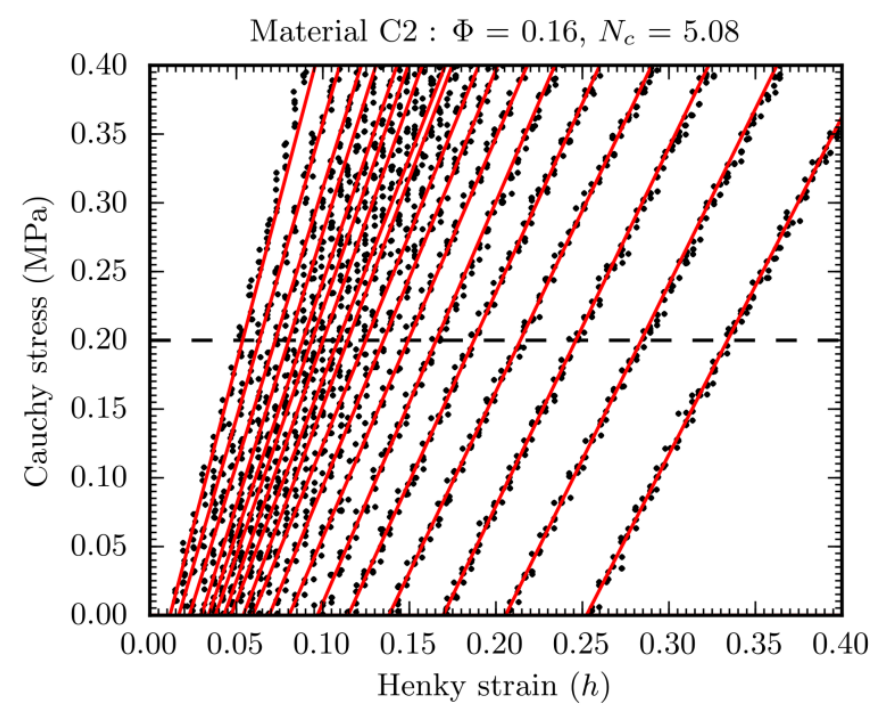

FIG. 7. Plot of the material C2 stress-strain unloading responses at small strains and their linear approximations used to estimate the initial tangent modulus. The dashed line materialized the upper stress limit used for the linear approximation.

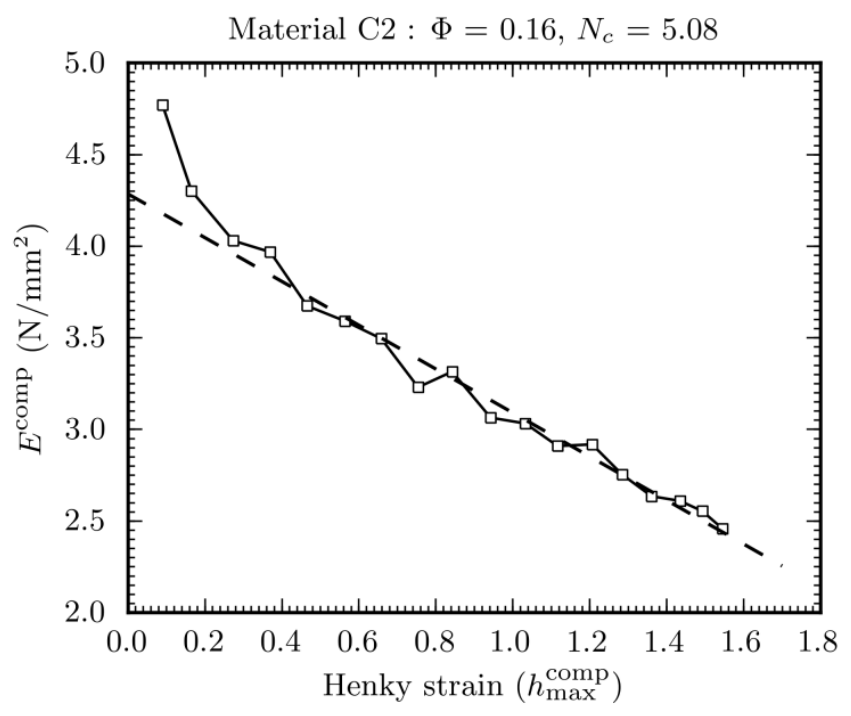

FIG. 8. Evolution of the tangent modulus at zero stress for the filled rubber $\mathrm{C} 2$ vs. maximum strain applied. 


\section{COMPARISON OF THE ESTIMATE OF THE SOFTENING PARAMETER $D$}

In theory, considering (2) and (5), the damage parameter $D$ values obtained from both methods should coincide. In practice, both methods do not use the same data. The tangent modulus is limited to the data covering a very limited range of the stress-strain response, while the strain amplification factor method uses the entire stress-strain response, which covers several hundred percent strain. Figure 9 shows a comparison of the values of parameter $D$ for the experimental data provided by the cyclic test conducted on material C2. Due to the large amount of data processed with the strain amplification factor method, results obtained by the latter appear smoother but both methods display similar results. The values of parameter $D$ show similar linear changes vs. the maximum strain applied when either the tangent modulus method or the strain amplification factor method is used. Therefore, the softening parameter $D$ introduced here defines an objective mean to characterize the Mullins softening quantitatively. We now use this parameter to examine how the Mullins softening of our materials evolves.

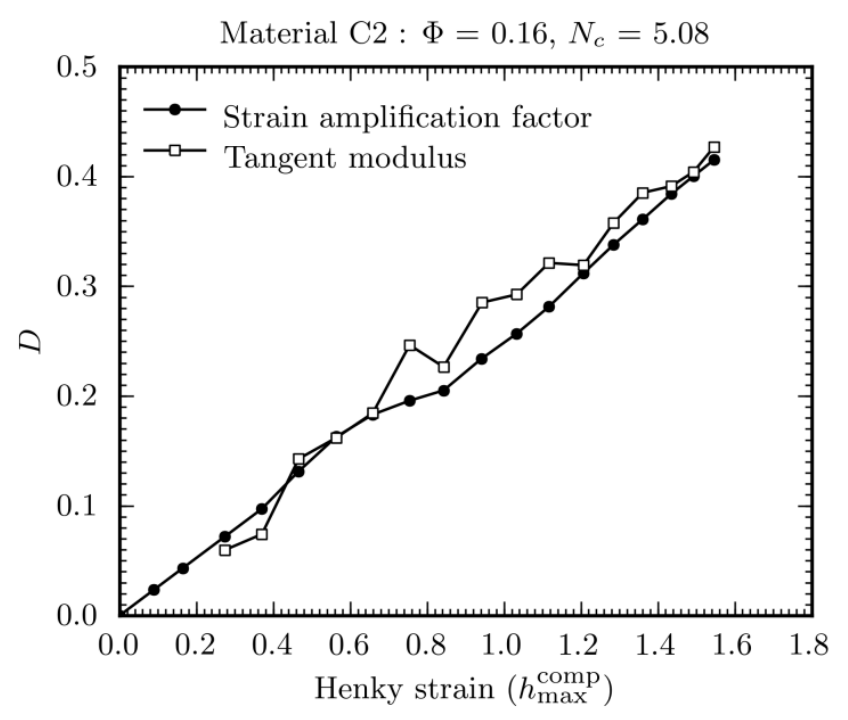

FIG. 9. Comparison of the damage parameter $D$ vs. the maximum strain applied, obtained by using either the strain amplification factor or the tangent modulus for material $\mathrm{C} 2$. 


\section{RESULTS AND ANALYSIS}

\section{EFFECT OF MATERIAL VISCOELASTICITY}
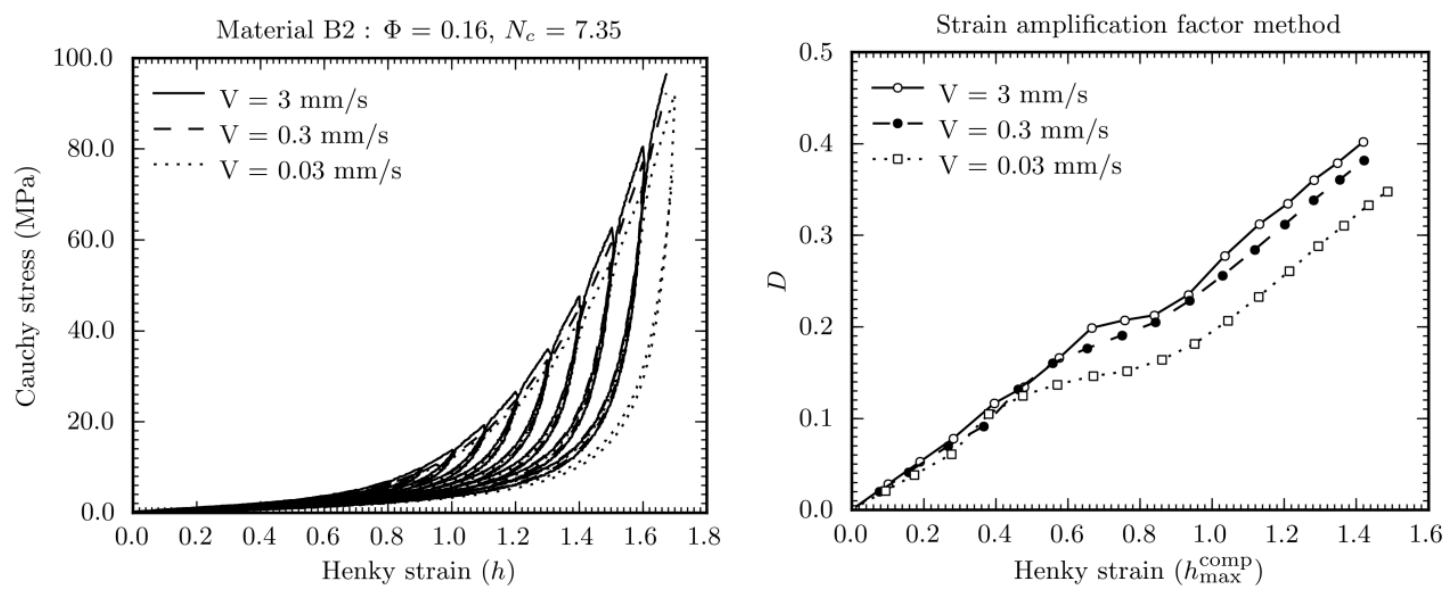

FIG. 10. Left: Effect of strain rate on the stress-strain response of material B2 during cyclic uniaxial tension. Right: Estimate of the Mullins softening according to the strain rate.

Filled rubbers are known to be viscoelastic materials. Previous contributions ${ }^{21-23}$ reported the strain rate effect on the stress-strain responses of filled rubbers but without proposing an objective comparison of the Mullins softening. In this section we want to investigate the impact of the viscoelastic properties of filled rubbers on the Mullins softening. For this purpose, we have submitted material B2 to cyclic loading tensile tests at various constant crosshead speeds, $0.03 \mathrm{~mm} / \mathrm{s}, 0.3 \mathrm{~mm} / \mathrm{s}$ and $3 \mathrm{~mm} / \mathrm{s}$ that provided strain rates close to $10^{-3} \mathrm{~s}^{-1}, 10^{-2} \mathrm{~s}^{-1}$ and $10^{-1} \mathrm{~s}^{-1}$ respectively. The strain ratedependent stress-strain responses appear in Figure 10. The damage $D$ was estimated according to the procedure described above and results are shown in Figure 10. The Mullins softening appears to be strain rate dependent at large strain, increasing with the increasing strain rate. In what follows, in order to study the impact of the amount of fillers and crosslink densities on the Mullins softening of filled SBRs, we will set the strain rate to $0.3 \mathrm{~mm} / \mathrm{s}$ for every test. 


\section{COMPARING MATERIALS OF DIFFERENT COMPOSITIONS}

The Mullins softening parameter $D$ was estimated according to the maximum strain applied $h_{\max }^{\operatorname{comp}}$ for each material listed in Figure 1, in order to study the effects of the crosslink density and of the filler fraction. On one side, we compared the softening measured in materials A2, B2, C2 and D2, which contain the same amount of fillers ( $40 \mathrm{phr}$ ) but have different crosslink densities (from 3.65 to $10.5510^{-5} \mathrm{~mol} / \mathrm{cm}^{3}$ ) and on the other side, the softening in materials $\mathrm{B} 1, \mathrm{~B} 2, \mathrm{~B} 3$ and $\mathrm{B} 4$, which contains $30,40,50$ and $60 \mathrm{phr}$ of carbon-black respectively and similar crosslink densities $\left(N_{c} \approx 7.10^{-5}\right.$ $\left.\mathrm{mol} / \mathrm{cm}^{3}\right)$.
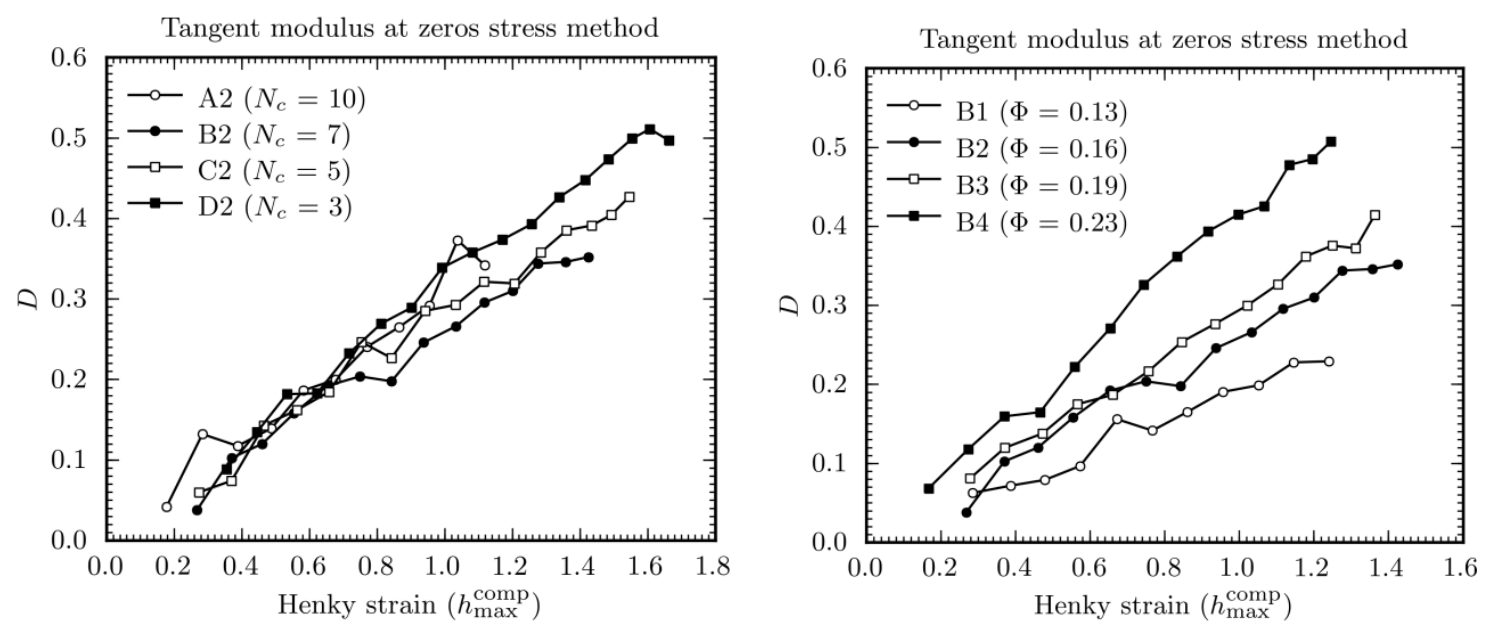

FIG. 11. Comparison of the Mullins softening $D$ vs. maximum applied Hencky strain for various carbon-black filled SBRs. Left: Effect of crosslink density for materials containing similar filler volume fractions $\Phi \approx 0.16$ (40 phr); Right: Effect of the amount of fillers for materials with similar crosslink densities $N_{c} \approx 7.10^{-5} \mathrm{~mol} / \mathrm{cm}^{3}$.

Figure 11 presents the change of $D$ evaluated on the modulus vs. the maximum strain applied for each material. One notes that changing the crosslink density did not affect significantly the Mullins softening. This result might be due to the fact that, with an entanglement density $\left(\sim 4210^{-5} \mathrm{~mol} / \mathrm{cm}^{3}\right)$ and the range of crosslink densities considered (between 3 and $1010^{-5} \mathrm{~mol} / \mathrm{cm}^{3}$ ), these networks are sufficiently crosslinked (physically and chemically) to evidence a similar softening. Here, the softening is characterized by the initial tangent modulus, which may be linked to the material crosslink 
density that may be measured by swelling and to the material entanglement density. Bokobza and Rapoport ${ }^{24}$ carried out measures of swelling on pre-stretched filled rubbers and showed an increase of the swelling ratio with the increase of the pre-stretched, which is equivalent to a decrease in the modulus. The decrease of the Young modulus is due to a reduction of the number of active physical or/and chemical crosslink. It is relevant to notice that the crosslink density was tuned by adding or withdrawing sulfur, and therefore without affecting the interface filler-matrix much.

In Figure 11, the amount of fillers is shown to have a considerable impact on the Mullins effect. By increasing the amount of filler, one increases drastically the Mullins softening. This result is in good agreement with several qualitative data that appear in the literature ${ }^{4,8,10,14,25-28}$. Let us notice that even though unfilled crystallizing rubbers like pure NR gum may show a clear Mullins ${ }^{29}$, the softening is observed for a substantially lower strain level when the material is filled. Non crystallizing rubbers like SBR break before Mullins softening appearance when unfilled ${ }^{29}$ therefore, the presence of a rigid phase is a requirement to observe some Mullins softening. Moreover, when uniformly dispersed in the rubber gum, fillers induce some Mullins softening when added them over a threshold. Tests conducted on our reference SBR gum filled with $5 \mathrm{phr}(\Phi=0.024)$ resulted in a Mullins softening close to null. This threshold is lowered when the rigid phase is structured, the structure increasing the strain heterogeneities ${ }^{30}$. AFM observations of the local strain in stretched filled rubbers showed a highly heterogeneous strain field and higher strains in regions where distances between aggregates are shorter $^{31}$. Bokobza ${ }^{32}$ compared the Mullins softening of SBR gums filled with silica with and without a silane coupling agent. Silane builds strong covalent bonds at the silica-gum interface and one notes that a strong filler-gum interface enhances the Mullins softening. Therefore, Mullins softening appears when the material microstructure favors highly strained regions. Moreover, the fact that strong bonding creates more Mullins effect than weak bonding shows that Mullins softening is not only due to the rupture of bonds at the filler-gum interface since the rupture is expected to be substantially larger for weak covalent bonds than strong ones. Bond ruptures at the gum-filler interface probably occur but other changes must take place. 
Another interesting aspect of the parameter $D$ is that it also provides a quantitative access to the phenomenon. Figures 11 shows that for our materials, the softening parameter is well approximated by:

$$
D=\alpha h_{\max }^{\operatorname{comp}}
$$

where parameter $\alpha$ depends on the filler amount only. Values of $\alpha$ may be reached from results reported in Figure 11, by a simple linear approximation. Results in regard to the filler fraction appear in Figure 12. Interestingly, the values of $\alpha$ vs. the filler fraction can be approximated by a linear law. The linear plot shown in Figure 12 corresponds to the relation:

$$
\alpha(\Phi)=2.25(\Phi-0.05)
$$

Such an approximation defines a filler volume fraction threshold $\Phi \approx 0.05$, below which the Mullins effect is expected to be negligible. Equations (9) and (10) combine into a surprisingly simple form for $D$,

$$
D=\beta\left(\Phi-\Phi_{0}\right) h_{\max }^{\operatorname{comp}}
$$

Let us note that parameters $\beta$ and $\Phi_{0}$ are probably dependent of the gum type, and of the filler nature and geometry, but this aspect was not investigated here. Equation (11) closes our quantitative estimate of the Mullins softening. Once its two parameters are determined, relation (11) authorizes the prediction of the Mullins softening for mixes with amounts of fillers not yet tested.

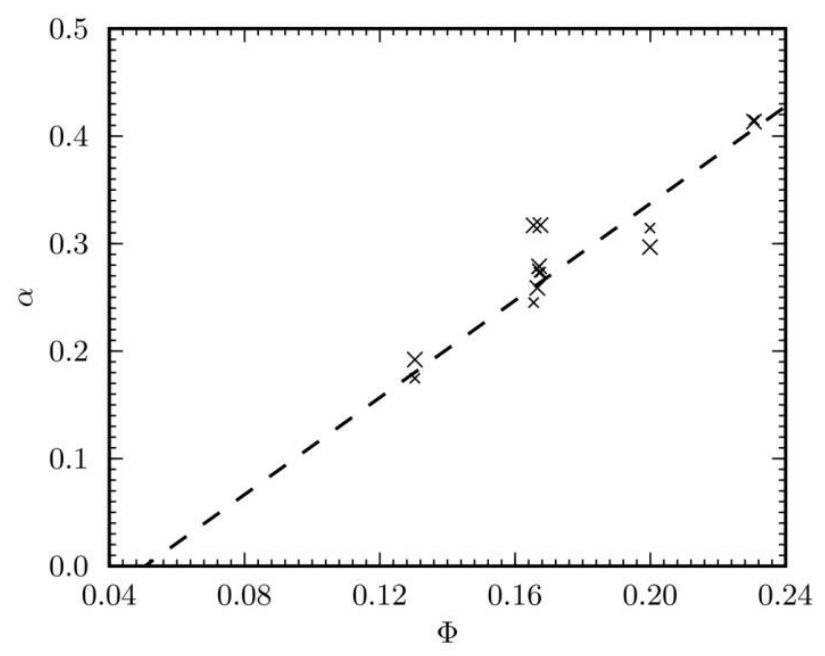


FIG. 12. Evolution of parameter $\alpha$ vs. the filler volume fraction for all materials

\section{CONCLUSION}

In this contribution, we have proposed a way to appraise the Mullins softening in order to quantitatively compare this specific damage observed in filled rubbers according to the material composition. A damage parameter $D$, which can be reached using the strain amplification factor by considering the material stress-strain response over the entire strain range or using the tangent modulus at zero stress, was introduced. This parameter provides an objective quantity to estimate and compare the Mullins softening. It was used to reflect the strain rate dependence of the Mullins softening and to study the effects of crosslink density and filler amount on the Mullins softening of SBR mixes. The crosslink density revealed a negligible impact on the Mullins softening, while increasing the filler fraction appeared to enhance the Mullins effect. Finally, the proposed softening parameter exhibited a mere linear change according to the maximum strain applied and also according to the filler fraction. This leads to a simple expression of the softening parameter that may predict the Mullins softening for other mixes that were not tested experimentally. We have investigated the effects of crosslink density and filler amount, but one may consider using the parameter $D$ to examine the consequences of changing the gum nature or the filler type and geometry.

\section{AKNOWLEDGEMENT}

This work was supported by grant MATETPRO08-320101 from the French Agence Nationale de la Recherche. The authors acknowledge their collaboration with D. Berghezan, C. Creton, J. de Crevoizier, F. Hild, M. Portigliatti, S. Roux, F. Vion-Loisel and H. Zhang.

\section{REFERENCES}

${ }^{1}$ H. Bouasse and Z. Carrière, Ann. Fac. Sci. Toulouse 5, 257 (1903)

${ }^{2}$ L. Mullins, J. Rubber Res. 16, 275 (1947) 
${ }^{3}$ L. Mullins, India Rubber World 6, 63 (1949)

${ }^{4}$ L. Mullins and N. R. Tobin, Rubber. Chem. Technol. 30, 555 (1957)

${ }^{5}$ L. Mullins, Rubber. Chem. Technol. 42, 349 (1969)

${ }^{6}$ J. Diani, B. Fayolle and P. Gilormini, Eur. Polym. J. 45, 601 (2009)

${ }^{7}$ J. C. Simo, Comput. Methods Appl. Mech. Solids 60, 153 (1987)

${ }^{8}$ M. Klüppel and J. Schramm, Macromol. Theory. Simul 9, 742 (2000)

${ }^{9}$ G. Markmann, E. Verron, L. Gornet, G. Chagnon, P. Charrier and P. Fort, J. Mech. Phys. Solids 50, $2011(2002)$

${ }^{10}$ A. Dorfmann and R. W. Ogden, Int. J. Solids Struct. 41, 1855 (2004)

${ }^{11}$ L. Mullins and N. R. Tobin, J. Appl. Polym. Sci. 9, 2993 (1965)

${ }^{12}$ M. A. Johnson and M. Beatty, Continuum Mech. Thermodyn. 5, 301 (1993)

${ }^{13}$ H. Qi and M. Boyce, J. Mech. Phys. Solids 52, 2187 (2004)

${ }^{14}$ H. Luo, M. Klüppel and H. Schneider, Macromolecules 37, 8000 (2004)

${ }^{15}$ B. Messier and L. Matějka, Polymer 47, 7997 (2006)

${ }^{16}$ B. Messier and L. Matějka, Eur. Polym. J. 32, 1940 (2008)

${ }^{17}$ M.J. Wang, S. Wolff S and Donnet JB. Rubber Chem. and Technol. 64, 714 (1991)

${ }^{18}$ H. M. Smallwood, J. Appl. Sci. 15, 758 (1944)

${ }^{19}$ A. Einstein, Ann. Physik. (Leipizig) 34, 591 (1911)

${ }^{20}$ J. S. Bergström, 'Large strain time-dependent behavior of elastomeric materials", Ph.D. thesis, Massachusetts institute of technology, (1999)

${ }^{21}$ G. Kraus, .W. Childers and K.W. Rollmann, J. Appl. Polym. Sci. 10, 209 (1966)

${ }^{22}$ M. Cheng and W. Chen, Int. J. Solids Struct. 40, 4749 (2003)

${ }^{23}$ A.M.F.S. Amin, A. Lion and P. Höfer, Zamm, 90, 347 (2010)

${ }^{24}$ L. Bokobza, O. Rapoport. J Appl Polym Sci 85, 2301 (2002)

${ }^{25}$ J. A. C. Harwood, L. Mullins and A. R. Payne, J. Appl. Polym. Sci. 9, 3011 (1965)

${ }^{26}$ J. A. C. Harwood and A. R. Payne, J. Appl. Polym. Sci. 10, 315 (1966)

${ }^{27}$ K. K. Kar and A. K. Bhowmick, Polymer Eng. Sci. 38, 1927 (1998)

${ }^{28}$ J. S. Bergström and M. C. Boyce, Rubber. Chem. Technol 72, 633 (1999)

${ }^{29}$ J.A.C. Harwood, L. Mullins, A.R. Payne, Rubber Chem Technol 39, 814 (1966)

${ }^{30}$ E. Coquelle, G. Bossis, D. Szabo, Giulieri F. J Mater Sci 41, 5941 (2006) 
Published in Rubber Chemistry and Technology (2011) vol. 84(3) pp 402-414

${ }^{31}$ A. Lapra, F. Clément, L. Bokobza, L. Monnerie, Rubber Chem Technol 76, 60 (2003)

${ }^{32}$ L. Bokobza, Macromol Mater Eng 289, 607 (2004) 